\title{
Three-dimensional Modelling of a Microtubular SOFC:
}

\section{A Multiphysics Approach}

\author{
O. Hodjati-Pugh ${ }^{\mathrm{a}}$, A. Dhir ${ }^{\mathrm{a}, \mathrm{b}}$, R. Steinberger-Wilkens ${ }^{\mathrm{a}}$ \\ ${ }^{\mathrm{a}}$ Centre for Fuel Cell and Hydrogen Research, \\ School of Chemical Engineering, University of Birmingham, B15 2TT \\ ${ }^{\mathrm{b}}$ School of Chemical Engineering, University of Wolverhampton, WVI $1 L Y$
}

Microtubular Solid Oxide Fuel Cells ( $\mu$-SOFC) are suited to a broad spectrum of applications with power demands ranging from a few watts to several hundred watts. $\mu$-SOFC's possess inherently favourable characteristics over alternate configurations such as high thermo-mechanical stability, high volumetric power density and rapid start-up times. Computational modelling at the design level minimises cost and maximises productivity, giving critical insight into complex SOFC phenomena and their interrelationships. To date, models have been limited by oversimplified geometries, often failing to account for oxidant supply complexities, gas distribution within pores and radiative heating effects (1-3).

Here, a three-dimensional Computational Fluid Dynamics (CFD) model of electrodes, electrolyte, current collectors and furnace is considered using COMSOL Multiphysics. The distribution of temperature, current density, electrical potential, pressure and gas concentrations throughout the cell are simulated. Results show good correlation with experimental data and the model is reliable for prediction of fuel cell performance within set parameters. 


\section{Introduction}

Portable electronic devices are becoming increasingly popular with applications from communication and data-processing to multimedia and gaming. The functionality of such devices is continually expanding, resulting in an increase in energy demand. Combined with the drive for compactness, battery life often enough is only sufficient for a few hours of usage. To remain mobile, on-the-go recharging is essential. A portable fuel cell system fits the criteria perfectly, delivering sustainably sourced electricity for the environmentally conscious user.

Fuel cells are high efficiency, electrochemical conversion devices that have the potential for 'zero emission' operation depending on the operating fuel and its source. Fuel cells are typically categorised on the nature of their electrolyte (solid/liquid), operating temperature (low/high) and geometry (tubular/planar). Two variants are suitable for portable applications, firstly, the Proton Exchange Fuel Cell (PEFC) which operates on high purity hydrogen at low temperatures $\left(50^{\circ} \mathrm{C}-100^{\circ} \mathrm{C}\right)$ with approximately 40-45\% electrical efficiency. Secondly, the Solid Oxide Fuel Cell (SOFC), which operates on hydrogen or carbonaceous fuels at high temperatures $\left(650^{\circ} \mathrm{C}-900^{\circ} \mathrm{C}\right)$ with 50 $55 \%$ electrical efficiency (4). Examples of commercially available fuel cell chargers include the PEFC powered Upp (5), and the SOFC powered Kraftwerk (which was eventually never produced) (6).

A tubular configuration of the SOFC is favoured in this study for its excellent performance and durability with peak power densities in literature around $1.3 \mathrm{~W} / \mathrm{cm}^{2}(7,8)$. Its inherent mechanical strength is well suited for withstanding the typical impacts encountered in everyday use of a portable power device. The micro-tubular configuration deals well with large thermal gradients and can handle short start-up times, ideal for providing near-instant power on demand (9). The internal reforming capability of SOFC's allows energy dense carbonaceous fuels to be used as an alternative to hydrogen. This reduces system size while alleviating fuel supply issues surrounding hydrogen infrastructure (10-12).

Research into $\mu$-SOFC can be categorised into the micro scale and macro scale with the overall goals of cost minimisation, performance maximisation and durability improvement (13). On the micro scale, atomic-molecular level studies are concerned with cell components, with notable topics including low-temperature electrolytes, electrode microstructure, and materials (14-16). On the macro scale, cell to stack component level studies centre around interconnection, sealing and manifolding (17-20). Studies can be empirical, numerical, or a combination of both. To address these study areas through simulation, complex underlying physical phenomena occurring during operation must be modelled. To date, very few published $\mu$-SOFC models include all physical phenomena: fluid flow, heat transfer, mass transfer, and charge transfer (13,21). Most only include one or two of these elements, yet interrelationship of the physics is unclear without including all. Even fewer studies are experimentally validated. Comprehensive tubular SOFC models include Lawlor et al's (22) validated single cell $\mu$-SOFC model which studied oxidant flow configuration and cathode current collection; Hajimolana et al's $\mu$ SOFC study on radiative heat transfer (23); Cui et al's current collection study (24), and Kee et al's current collection network study (25). 
Multiphysics models can be computationally intensive and so models are usually oversimplified. This reduces computational time, narrowing the validity and functionality of the model by making assumptions, resulting in significant deviations from reality. The work presented here entails the construction of a comprehensive $\mu$-SOFC model. This mirrors an experimental setup as a low cost, flexible design tool for the rapid prototyping of interconnections. The model will be used as a precursor to a stack model with optimised thermal management and interconnect architecture. This uses the knowledge attained from the single cell model to make informed simplifications where possible.

\section{Scientific Approach}

\subsection{Cell Specification}

The tubular fuel cell used for the study was a state-of-the-art cell supplied by AMI. The total fuel chamber length was $150 \mathrm{~mm}$. Both electrodes have a reaction and functional layer, with the anode being Ni-YSZ, the cathode as YSZ/LSM and LSM, and a YSZ electrolyte. Figure 1a shows a 3D representation of the $\mu$-SOFC in the furnace. Figure $1 b$ shows a hemispherical slice of the inlet side of the $3 \mathrm{D} \mu$-SOFC in the furnace The geometry is split axially.

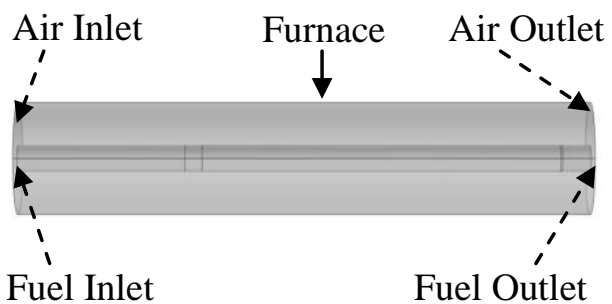

Figure 1a: 3D $\mu$-SOFC Geometry

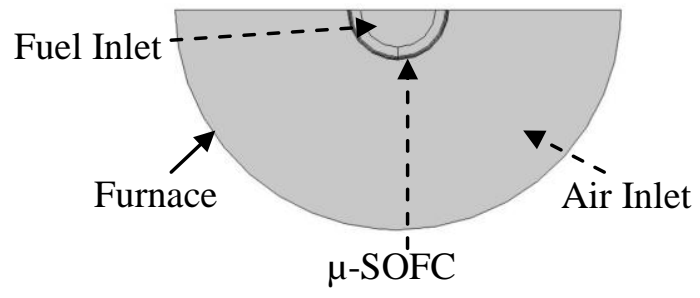

Figure 1b: Inlet Side Geometry Slice

\subsection{Cell Mesh}

COMSOL Multiphysics uses the Finite Element Method (FEM) to evaluate the approximations to the momentum, heat, mass and charge conservation Partial Differential Equations (PDE). The 3D configuration was meshed with a custom computational mesh with $70 \%$ element quality. The symmetry of the $\mu$-SOFC, current collection configuration, and heat transfer assumptions mean that a hemispherical slice along the axis of the tube is a reasonable representation of the whole cell in the furnace. Figure $2 \mathrm{a}$ is the model mesh element quality distribution $(0 \leq 1)$ of the whole $3 \mathrm{D} \mu$-SOFC geometry seen in Figure $1 \mathrm{a}$. The quality of mesh is close to one, hence the light grey-white colouring. Figure $2 b$ is zoom of the mesh used for $\mu$-SOFC geometry. 


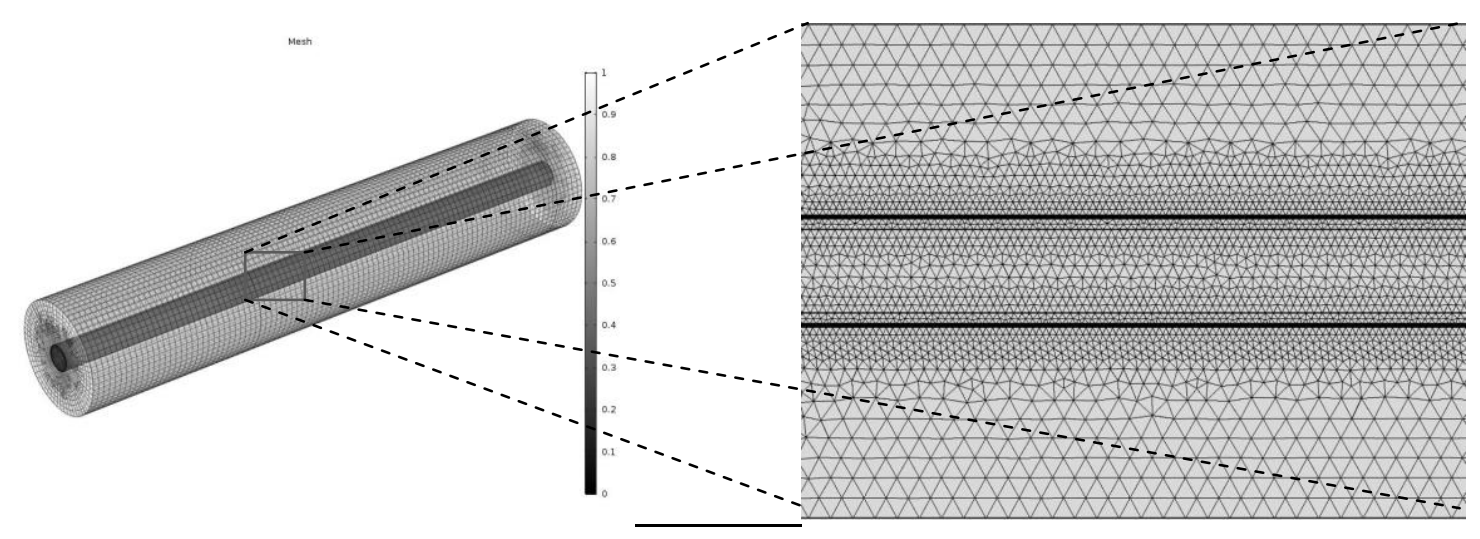

Figure 2a: 3D $\mu$-SOFC Mesh Quality

Figure 2b: Zoom of 3D $\mu$-SOFC Mesh

\subsection{Modelling Strategy}

The commercial CFD package COMSOL Multiphysics 5.2a is the software used for this simulation. The physics is grouped into modular packages most suited to their respective application. The Batteries and Fuel Cells, CFD and Chemical Reaction Engineering modules were required and Table I lists the equations and domains the modules were applied to. Equations can be found in the handbook [25].

TABLE I. COMSOL 5.2 Module Selection

\begin{tabular}{|c|c|c|}
\hline $\begin{array}{c}\text { COMSOL 5.2 } \\
\text { Multiphysics Module }\end{array}$ & Equations & Domains \\
\hline Laminar Flow & - Momentum Balances & - Anode and Cathode Gas Channels \\
\hline $\begin{array}{l}\text { Free \& Porous Media } \\
\text { Flow }\end{array}$ & - Momentum Balances & $\begin{array}{l}\text { - Porous Anode and Cathode } \\
\text { (diffusion \& reaction) }\end{array}$ \\
\hline Heat Transfer in Fluids & $\begin{array}{ll}- & \text { Energy Balance } \\
\text { - } & \text { Convective Heat Transfer } \\
& \text { Coefficient }\end{array}$ & - Anode and Cathode Gas Channels \\
\hline $\begin{array}{c}\text { Heat Transfer in Porous } \\
\text { Media }\end{array}$ & $\begin{array}{ll}- & \text { Energy balance } \\
\text { - } & \text { Convective Heat Transfer } \\
& \text { Coefficient }\end{array}$ & $\begin{array}{l}\text { - Porous Anode and Cathode } \\
\text { (diffusion \& reaction) } \\
\text { - Electrolyte } \\
\text { - Anode and Cathode Current } \\
\text { Collectors }\end{array}$ \\
\hline $\begin{array}{c}\text { Transport of } \\
\text { Concentrated Species }\end{array}$ & $\begin{array}{ll}\text { - } & \text { Mass Balances } \\
\text { - } & \text { Diffusion and Convection } \\
\text { - } & \text { Density of Gases }\end{array}$ & $\begin{array}{l}\text { - Gas Channels } \\
\text { - Porous Anode and Cathode } \\
\text { (diffusion \& reaction) }\end{array}$ \\
\hline Current Distribution & $\begin{array}{ll}\text { - } & \text { Electrochemical Reactions } \\
\text { - } & \text { Ionic And Electric Charge } \\
\text { Balances } \\
\text { - Heat Generation - Power } \\
\text { Dissipation } \\
\text { - Heat Generation -Reaction }\end{array}$ & $\begin{array}{l}\text { - Porous Anode and Cathode (diffusion } \\
\text { \& reaction) } \\
\text { - Electrolyte } \\
\text { - Anode and Cathode Current } \\
\text { Collectors }\end{array}$ \\
\hline
\end{tabular}




\section{Mathematical Modelling Approach}

\section{$\underline{2.1 \text { Conservation of Momentum }}$}

The Laminar Flow module in COMSOL Multiphysics uses the Navier-Stokes equation for describing the momentum balance of gases in the anode and cathode gas channels:

$$
\rho(u \nabla) u=\nabla\left[-P I+\mu\left(\nabla u+(\nabla u)^{T}-\frac{2}{3} \mu(\nabla u) I\right)\right]+F_{b}
$$

The gases are assumed to be compressible with Ma $<0.3$ and so the steady-state continuity equation, used in conjunction, is in the form:

$$
\nabla(\rho u)=0
$$

The Free and Porous Media module is used to describe the flow in the electrodes, utilising an extended Navier-Stokes equation called the Brinkman equation which accounts for the porosity and permeability of the electrodes:

$$
\frac{\rho}{\epsilon}(u \nabla) \frac{u}{\varepsilon}=\nabla\left[-P I+\frac{\mu}{\varepsilon}\left(\nabla u+(\nabla u)^{T}-\frac{2 \mu}{3 \varepsilon}(\nabla u) I\right)\right]-\left(\frac{\mu}{\kappa}+\beta_{F}|u|+\frac{Q_{b r}}{\varepsilon^{2}}\right)+F_{b}
$$

Where $\nabla$ is the del operator, $\rho$ is the fluid density $\left[\mathrm{kg} / \mathrm{m}^{3}\right], u$ is the velocity vector $[\mathrm{m} / \mathrm{s}], p$ is the pressure of the fluid $[\mathrm{Pa}], \mathrm{I}$ is the identity matrix $[-], \mu$ is the dynamic viscosity $[\mathrm{Pa} \cdot \mathrm{s}], \kappa$ is the permeability $\left[\mathrm{m}^{2}\right], \varepsilon$ is the porosity $[-], \mathrm{F}_{\mathrm{b}}$ is the volume force vector $\left[\mathrm{N} / \mathrm{m}^{3}\right]$, and $\mathrm{T}$ is the transpose matrix $[-]$.

A new Brinkman effective viscosity $\left(\beta_{F}\right)$ term, $[\mathrm{Pa} \cdot \mathrm{S}]$, is introduced and is assumed to be the dynamic viscosity of the gaseous mixtures in the fuel cell. The second term in the square brackets is the viscous stress tensor, $\tau\left[\mathrm{N} / \mathrm{m}^{2}\right]$. An additional species source term $\left(Q_{b r}\right),\left[\mathrm{kg} /\left(\mathrm{m}^{2} \cdot \mathrm{s}\right)\right]$, is also introduced and results in a varying gas composition in the anode and cathode streams, implying that density and velocity are no longer constant:

$$
\nabla(\rho u)=Q_{b r}
$$

\subsection{Conservation of Energy}

The overall energy balance of the $\mu$-SOFC model is given by:

$$
\rho C_{p} \boldsymbol{u} \cdot \nabla T+\nabla \cdot \boldsymbol{q}=Q+Q_{\text {cond }}
$$

Where $\rho$ is the fluid density $\left[\mathrm{kg} / \mathrm{m}^{3}\right], u$ is the velocity vector $[\mathrm{m} / \mathrm{s}], \mathrm{C}_{\mathrm{p}}$ is the specific heat capacity at constant pressure $[\mathrm{J} /(\mathrm{kg} \cdot \mathrm{K})]$. The heat transfer by conduction is given by Fourier's Law:

$$
q=-\lambda \nabla T
$$


The heat transfer coefficient is denoted by $\lambda\left[\mathrm{W} /\left(\mathrm{m}^{2} \cdot \mathrm{K}\right)\right]$. Within the porous electrode media:

$$
q=-k_{e f f} \nabla T
$$

Where $\mathrm{k}_{\text {eff }}$ is an effective coefficient $[\mathrm{J} /(\mathrm{kg} \cdot \mathrm{K})]$, using volume fraction $\theta$ to consider convection contribution in the pore and void:

$$
k_{\text {eff }}=\theta_{p} k_{p}+\left(1-\theta_{p}\right) k
$$

Heat transfer by radiation occurs from surface to surface exchange and from participating media is Equation [9]. The radiative heat transfer has yet to be included in this model but is the next phase for the transition to a complete heat transfer model:

$$
q_{\text {rad }}=\varepsilon \sigma\left(T_{s}^{4}-T_{s u r}^{4}\right)
$$

Where $\varepsilon$ is the emissivity [-], $\sigma$ is the Stefan-Boltzman constant $\left[\mathrm{W} \cdot \mathrm{m}^{-2} \cdot \mathrm{K}^{-4}\right], \mathrm{T}$ is temperature $[\mathrm{K}]$. The $\mathrm{Q}$ term represents the volumetric heat source representing the heat generation, where the lower case, $\mathrm{q}$ is the heat flux per area. Within the porous electrode reaction layers, exothermic electrochemical reactions produce heat. Heat generation is from irreversible and reversible loss and power dissipation, arising from the resistance of ion and electron movement within the solid and porous media. The overall equation is given by:

$$
q_{g}=q_{\text {irrev }}+q_{o h}+q_{p d}
$$

The irreversible heat flux is given by the product of voltage overpotential and the local current:

$$
q_{\text {irrev }}=I_{v} \eta
$$

Ohmic heat is generated by power dissipation when drawing the electric current and is given by:

$$
q_{o h}=\nabla\left(I_{s} \phi_{s}\right)
$$

Where $\nabla$ is the del operator, I is the current $[\mathrm{A}], \Phi$ is the electric/ionic potential [V], and $\eta$ is the overpotential [V].

At this stage of the model, the assumption of no ion flow through the electrolyte and no consumption/generation means no power is dissipated in the electrolyte, giving:

$$
q_{p d}=\nabla\left(I_{I} \phi_{I}\right)
$$

The energy balance equations for the specific domains are shown in Table II. 
TABLE II. Model Component Equations

\begin{tabular}{|c|c|c|}
\hline $\begin{array}{c}\text { Model Component } \\
\text { channels }\end{array}$ & Energy Balance Equation & \\
\hline $\begin{array}{c}\text { Anode and Cathode gas } \\
\text { layers }\end{array}$ & $\rho C_{p} u \nabla T_{g c}=\nabla\left(k \nabla T_{g c}\right)+h_{g c}\left(T_{g c w}-T_{g c}\right)$ & {$[14]$} \\
\hline $\begin{array}{c}\text { Electrode reaction } \\
\text { layers }\end{array}$ & $C_{p} u \nabla T_{g c w}=\nabla\left(k \nabla T_{g c w}\right)+h_{g c}\left(T_{g c}-T_{g c w}\right)+\nabla\left(I_{s} \phi_{s}\right)$ & {$[15]$} \\
\hline Electrolyte & $\nabla \nabla T=\nabla(k \nabla T)+h_{g c}\left(T_{g c}-T\right)+I_{v} \eta+\nabla\left(I_{s} \phi_{s}\right)+\nabla\left(I_{I} \phi_{I}\right)$ & {$[16]$} \\
\hline $\begin{array}{c}\text { Anode Interconnect } \\
\text { Cathode Interconnect }\end{array}$ & $\nabla(k \nabla T)+\nabla\left(I_{I} \phi_{I}\right)=0$ & {$[17]$} \\
\hline
\end{tabular}

\subsection{Conservation of Mass}

The law of mass conservations states that mass cannot be created nor destroyed and is the governing equation for mass transfer throughout the $\mu$-SOFC. The diffusion and convection model in this report applies the law to gases in the anode and anode gas channel separately to the cathode and furnace chamber. The model also accounts for transfer restrictions from the tortuous flow paths through the porous electrodes. Oxygen ion diffusion is neglected in this model meaning hydrogen reduction is not proportional to oxide ion concentration. The mass balance is therefore:

$$
\nabla J_{A}+\rho(u \cdot \nabla) \omega_{A}=R_{A}
$$

Where $\mathbf{J}$ is the mass flux $\left[\mathrm{kg} /\left(\mathrm{m}^{2} \cdot \mathrm{s}\right)\right], \rho$ is the density $\left[\mathrm{kg} / \mathrm{m}^{3}\right]$, and $\omega$ is the mass fraction. Three mass transport models, the Fick's model (FM), Stefan-Maxwell Model (SMM), and dusty-gas model (DGM) are reasonable approximations for simulating mass transfer within the $\mu$-SOFC. The DGM is the best approximation for all operating conditions and accounts for Knudsen diffusion, which describes interactions between the pore wall and the fluid. However, when operating at low current, high reactant concentration and with a large pore size, the less computationally intensive FM and SMM are deemed an appropriate approximation. The SMM is therefore used as a precursor to the DGM implementation for comparison in later research. Equations are solved in the gas channels and the porous electrodes:

$$
I_{A}=-\left(\rho \omega_{A} D_{A}^{m}+\rho \omega_{A} D_{A}^{m} \frac{\nabla M_{n}}{M_{n}}\right)
$$

Where $\mathrm{D}$ is the diffusion coefficient $\left[\mathrm{m}^{2} / \mathrm{s}\right], \mathrm{M}$ is the molar mass $[\mathrm{kg} / \mathrm{kmol}]$, and the diffusivity is given by: 


$$
D_{A}^{m}=\frac{1-\omega_{A}}{\sum_{k \neq A} \frac{\chi_{A}}{D_{A B}}}
$$

The binary diffusivity of the gases are calculated using the Fuller equation for both the anode and cathode gas channel (27):

$$
D_{A B}=\frac{1 \times 10^{-7} T^{1.75}\left(\frac{1}{M_{A}}+\frac{1}{M_{B}}\right)}{P\left(V_{A}^{1 / 3}+V_{B}^{1 / 3}\right)^{2}}
$$

Where $\mathrm{V}$ is the diffusion volume $\left[\mathrm{m}^{3}\right], \mathrm{P}$ is the pressure [Pa], and $\tau$ is the tortuosity [-]. However, the diffusivity of the gases is limited by the pores in the anode and cathode. Therefore, an effective diffusivity is used and is given by:

$$
D_{A B . e f f}=D_{A B} \varepsilon^{1.5}
$$

The DGM differs by considering an alternative effective diffusivity, combining the binary diffusivity in Equation [23] with the Knudsen diffusivity below:

$$
D_{i K}=\frac{97}{2} d_{\text {pore }} \sqrt{\frac{T}{M_{i}}}
$$

Where $\mathrm{d}$ is diameter $[\mathrm{m}], \mathrm{T}$ is temperature $[\mathrm{K}], \varepsilon$ is porosity [-]. Adjusting for the porosity, $\varepsilon$, as well as permeability, $\tau$, in the following weighting equation:

$$
D_{i}^{e f f}=\frac{\varepsilon}{\tau}\left(\frac{1}{D_{i j}}+\frac{1}{D_{i K}}\right)^{-1}
$$

\subsection{Conservation of Charge}

The charge balances are conducted in the electrochemical model. For the electrode diffusion layer and the current collectors, the electric charge balance is given by:

$$
\nabla I_{s}=-\nabla\left(\sigma_{s} \nabla \phi_{s}\right)
$$

Where $\sigma$ is the ionic/electric conductivity [S/m], $\Phi$ is the ionic/electric potential [V], and I is the current $[\mathrm{A}]$. The ionic charge balance does not apply to the electrode diffusion layers and interconnects as no reaction occurs there and therefore, no species are consumed or produced. Although the anode and cathode areas of the SOFC are modelled separately, an ionic charge balance can be done for the electrolyte:

$$
\nabla I_{I}=-\nabla\left(\sigma_{I} \nabla \phi_{I}\right)
$$

For the porous electrode reaction layer, a current is generated due to the consumption and production of the electrons at the cathode and anode respectively. Therefore, the change in the electric current density is given by: 


$$
\nabla I_{s}=\sum_{x} i_{v \cdot x}=\nabla\left(\sigma_{s} \nabla \phi_{s}\right)
$$

The ionic current density has the same form as the electron current density and is given by:

$$
\nabla I_{I}=\sum_{x} i_{v \cdot x}=-\nabla\left(\sigma_{I} \nabla \phi_{I}\right)
$$

A modified version of the Butler-Volmer equation is used involving the concentration kinetics of the gas species in order to calculate the local current densities in the anode and cathode seen in Equation [30]. The concentration is calculated using the ideal gas equation:

$$
I_{\text {loc }}=I_{o}\left(\frac{C_{R}}{C_{R i}} \exp \left(\frac{\alpha_{a} F \eta}{R T}\right)-\frac{C_{o}}{C_{O i}} \exp \left(\frac{-\alpha_{c} F \eta}{R T}\right)\right)
$$

Where $\mathrm{C}$ is the concentration $\left[\mathrm{mol} / \mathrm{m}^{3}\right], \alpha$ is the electron transfer coefficient [-], $\mathrm{F}$ is Faraday's constant $[\mathrm{C} / \mathrm{mol}], \eta$ is the overpotential $[\mathrm{V}], \mathrm{R}$ is the Avogadro constant $\left[\mathrm{mol}^{-1}\right]$, and $\mathrm{T}$ is the temperature $[\mathrm{K}]$.

The local volumetric current density must then be calculated to determine the electrochemical reaction rates. The equation for this is based on the specific area of the electrode and the local current density:

$$
I_{v, x}=A_{s} I_{l o c}
$$

The current exchange density $\left(I_{o}\right)$ and specific are $\left(A_{s}\right)$ are fitting parameters which are used to fit the model cell to current and voltage data to the experimental data. This is due to these parameters not being known and therefore, trial and error must be used to the model data.

The overpotential for the anode and cathode are given by the following equation:

$$
\eta=\phi_{s}-\phi_{l}-V_{e q}
$$

The voltage of the cell is calculated based on the equilibrium voltages of the anode and cathode as well as the voltage polarisation:

$$
V_{\text {cell }}=V_{\text {eq.c }}-V_{e q . a}-V_{\text {pol }}
$$

Where $\mathrm{V}$ is the voltage $[\mathrm{V}]$.

\subsection{Boundary Conditions}

The fuel, hydrogen with $3 \%$ humidity, enters with a volumetric flowrate of $3.333 E-7$ $\mathrm{m}^{3} / \mathrm{s}$ at the left-hand side of the geometry seen in Figure 1a, with a temperature of $873 \mathrm{~K}$. The air also enters the furnace at the left-hand side of the geometry assuming a co-flow arrangement. The entering air is at $298.15 \mathrm{~K}$ and a $15 \mathrm{~Pa}$ pressure drop is assumed across the furnace for a suppressed backflow. Furnace air bulk temperature is set at $1023 \mathrm{~K}$. In 
some of our studies, cells are modelled as $3 \mathrm{~W}$ to $15 \mathrm{~W}$ heat source. These particular boundary conditions were applied to be as similar as possible to the experimental setup and results (28).

\section{Results and Discussion}

Figure 3 shows the temperature distribution of the cell inside the furnace. The overall temperature gradients are greatest near the inlet side and the range spans from $300 \mathrm{~K}$ to $1300 \mathrm{~K}$. The temperature span of the electrodes is between $930 \mathrm{~K}$ and $1020 \mathrm{~K}$. The cold air and fuel streams are rapidly heated with the temperature difference decreasing axially. A lower fuel flow rate results in less cooling by the fuel flow in addition to less heat produced from reactions. At lower fuel flow rates, fuel outlet temperature will be elevated.

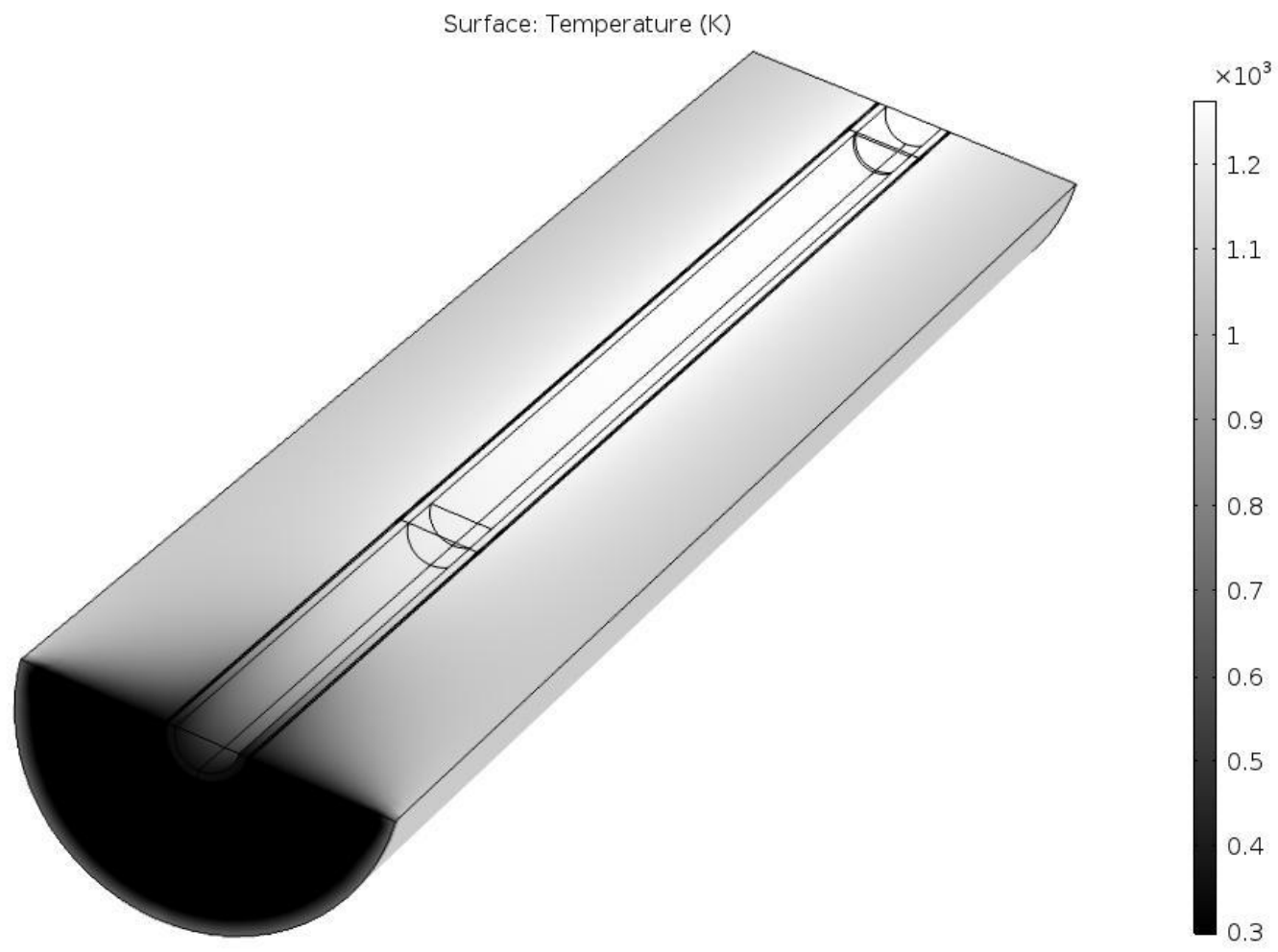

Figure 3: Temperature distribution in $\mu$-SOFC and furnace.

The velocity profiles of air inside the furnace is shown in Figure 4a. A symmetric flow distribution is observed, as expected. The velocity at the furnace interior wall and at the boundary between the cathode and electrolyte is zero, shown by dark shading. Overall, the velocity inside the furnace ranges from $0 \mathrm{~m} / \mathrm{s}$ (black) to $0.014 \mathrm{~m} / \mathrm{s}$ (white).

Figure $4 \mathrm{~b}$ shows the velocity through the anode channel. The velocity profile is symmetrical as expected. The velocity is zero near the electrolyte, adhering to the no-slip boundary condition at the wall. The velocity ranges between $0 \mathrm{~m} / \mathrm{s}$ (black) and $0.12 \mathrm{~m} / \mathrm{s}$ (white). The fuel flow rate in the channel is set based on the desired fuel utilisation for a given current output. 


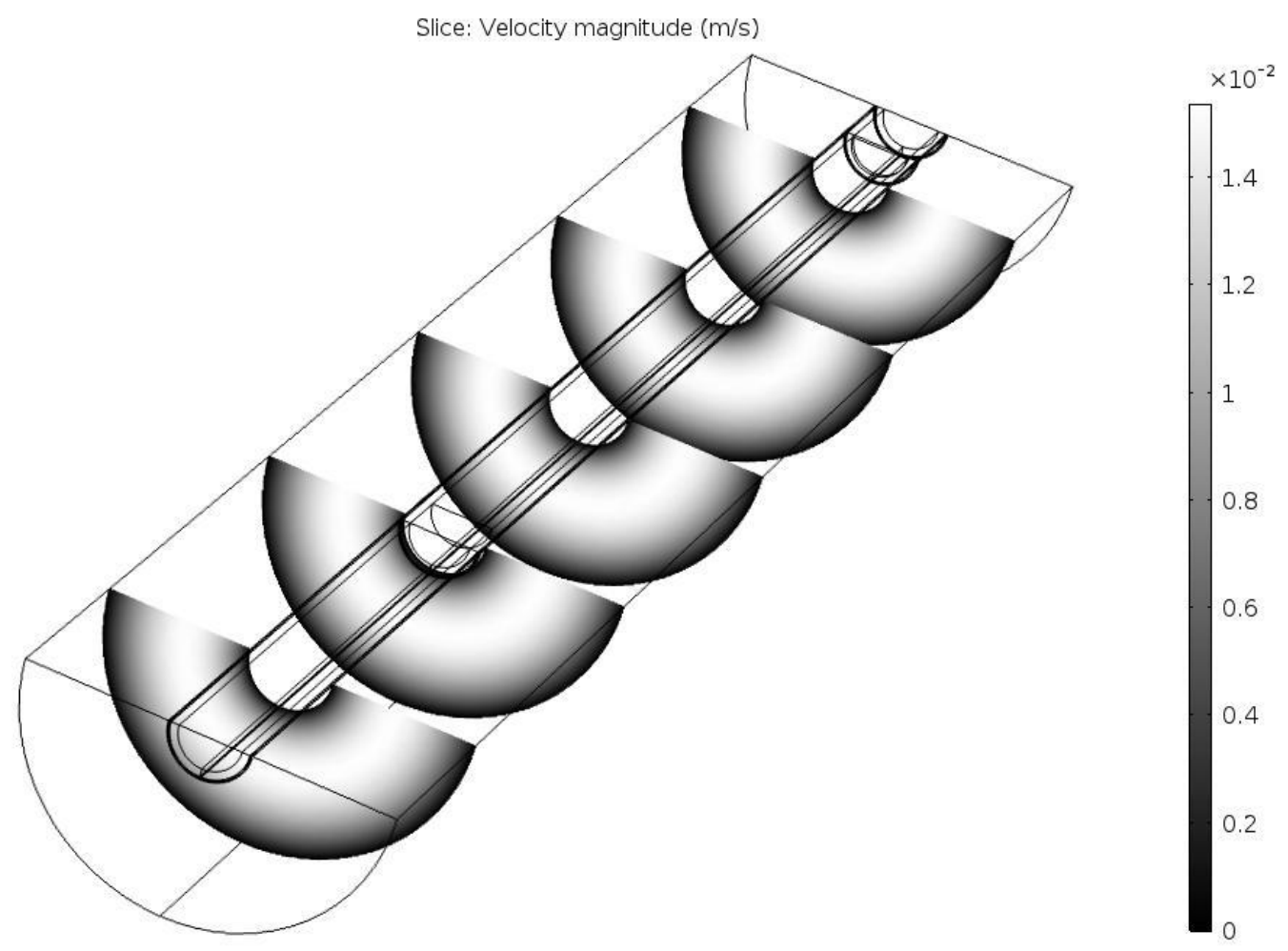

Figure 4a: Velocity profile in the furnace.

Slice: Velocity magnitude $(\mathrm{m} / \mathrm{s})$

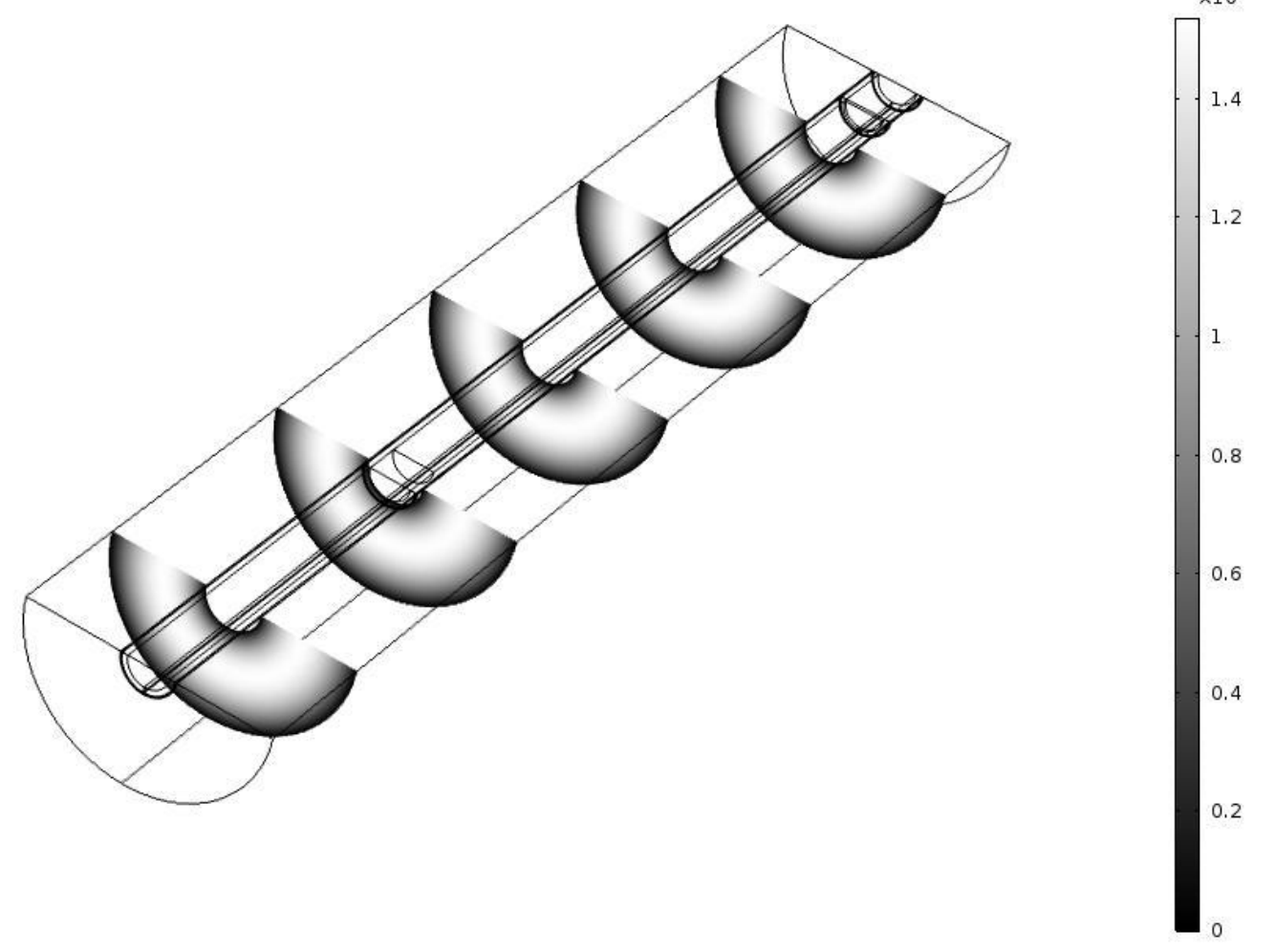

Figure 4b: Velocity profile in the anode channel 
Figure 5 shows the polarisation curve and power curve predicted by the $\mu$-SOFC model. The cell voltage (CV) and average power density (APD) of the cell are plotted against the average current density. The operating temperature of the furnace was $1023 \mathrm{~K}$. The in-house experimental results at matching operating conditions are overlaid with a $3 \%$ humidified hydrogen flow of $3.333 E-7 \mathrm{~m}^{3} / \mathrm{s}$ at $1023 \mathrm{~K}(28)$.

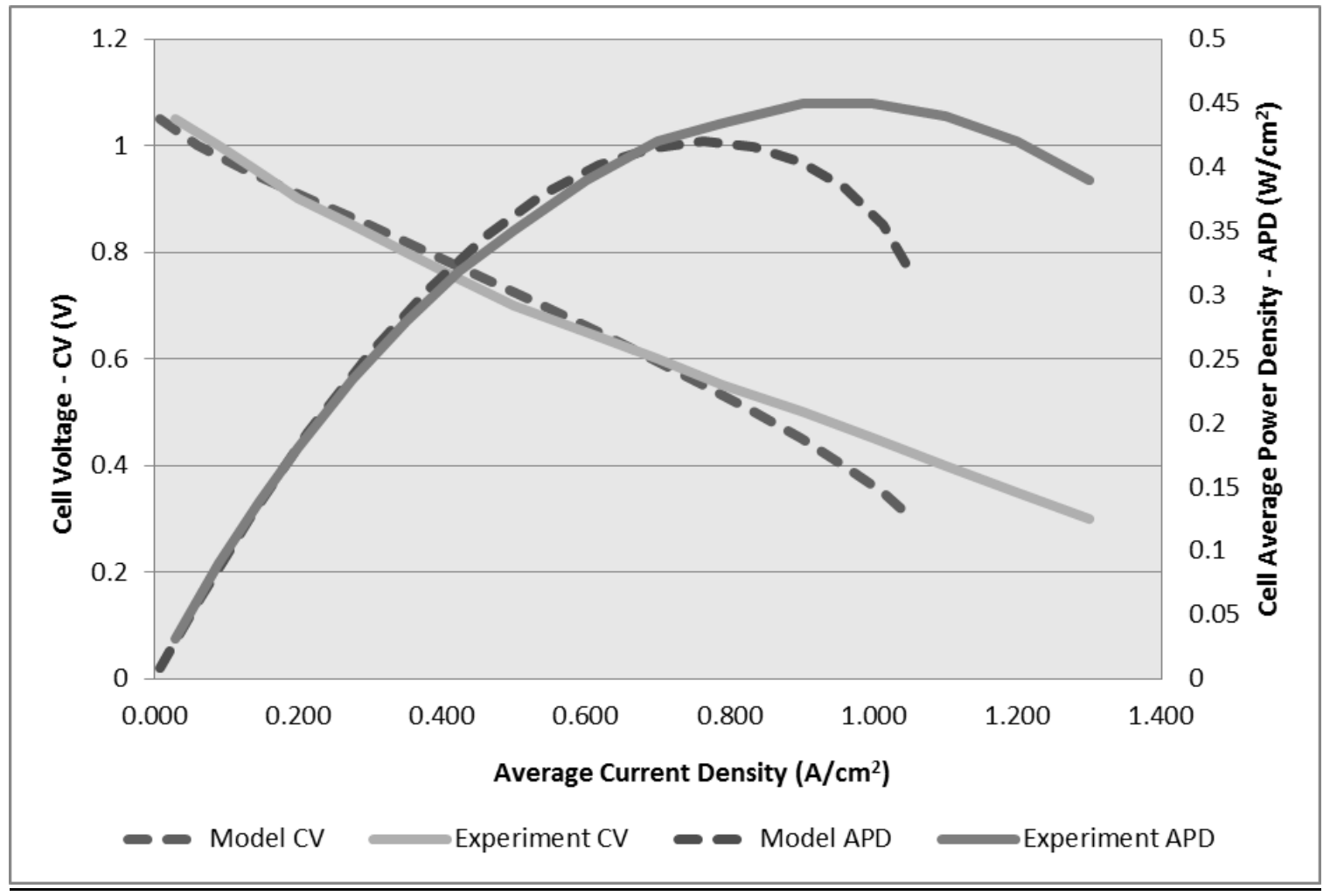

Figure 5: Model vs Experimental - Power and CV Curves.

The model and experimental polarisation curves show the typical profile of an SOFC, cell voltage decreasing as average current density increases. The low current density regions are dominated by activation loss, the medium region dominated by linear conduction loss and the high current density region dominated by concentration/mass transport loss. The simulation $\mathrm{CV}$ shows good correlation to the experimental results between $0.65 \mathrm{~V}-1.05 \mathrm{~V}$. Below $0.65 \mathrm{~V}$, results diverge with the model under predicting the average current density by $18 \%$ at a voltage of $0.3 \mathrm{~V}$. The model predicted that a maximum power density of $0.42 \mathrm{Wcm}^{-2}$ at $0.6 \mathrm{~V}$. Empirical results gave a maximum power density of $0.45 \mathrm{Wcm}^{-2}$ at a lower operating voltage of $0.5 \mathrm{~V}$.

Divergence at lower cell voltage is likely due to low hydrogen concentrations at the latter parts of the cell, indicating a further refinement of the concentration loss assumptions is required. In addition, upgrading of the mass transfer model to the DGM should bring the simulations closer to reality. The DGM will account for Knudsen diffusion, simulating the interaction between species and the pore walls and the associated losses. Interestingly, the Fuller Equation [23] has an error of 5.1\% which will result in some deviation (29). Error from experimental data must also be considered. This can be reduced with a standardised testing procedure. 


\section{Concluding Remarks and Further Work}

The $\mu$-SOFC model framework has been set up in 3D, including whole and slice geometries. The model includes conservation of momentum, energy, mass and charge. Some simplifying assumptions have been made in the mass transfer, charge transfer, and heat transfer modules. These will be improved incrementally, bringing the simulation closer to our experimental results. This will be done by:

- Upgrading the mass transfer model from SMM to DGM to account for Knudsen diffusion,

- Reducing assumptions in charge transfer model around anode side oxygen concentration,

- Including radiative heating effects from participating media and surface to surface interactions, and

- Fitting to large data sets from in-house 'mirroring' experimentation to widen the validity and predictability range of the model.

A refined model will then be used to explore the effect of interconnection on cell performance, species concentrations and temperature distribution. A fitted single cell model is a prerequisite for a multiphysics stack model. The stack model will use knowledge attained from the single cell model to make simplifications, where possible. This will reduce computational intensity, suitable for integration into a control system, with a particular focus on thermal management.

\section{Acknowledgement}

This work was funded and supported by the Centre for Doctoral Training (CDT) for Fuel Cells and their Fuels as part of the EPSRC grant EP/L015749/1.

\section{References}

[1] D. Cui, B. Tu, and M. Cheng, J. Power Sources, 297, 419-426 (2015).

[2] M. Lockett, M. J. H. Simmons, and K. Kendall, J. Power Sources, 131, 243-246 (2004).

[3] S. Kakaç, A. Pramuanjaroenkij, and X. Y. Zhou, Int. J. Hydrogen Energy, 32, 761-786 (2007.

[4] R. O'Hayre, Suk-Won Cha, Whitney Colella, Fuel Cell Fundamentals, p. 261-286, John Wiley \& Sons, New York (2009).

[5] Intelligent Energy, Available: http://www.intelligent-energy.com/ourfocus/consumer-electronics/overview/. [Accessed: 04-Apr-2017].

[6] Kraftwek, Available: https://www.kickstarter.com/projects/ezelleron/kraftwerkhighly-innovative-portable-power-plant. [Accessed: 04-Apr-2017].

[7] H. Luebbe, J. Silva, and J. Van, Fuel Cells, 15(5), p. 98-104, (2015).

[8] T. Suzuki, T. Yamaguchi, Y. Fujishiro, and M. Awano, Journal of The Electrochemical Society, 153 (5), p. 925-928 (2006).

[9] K. Kendall and A. Meadowcroft, International Journal of Hydrogen Energy, 38 (2013).

[10] K. Eguchi, Solid State Ionics, (152-153), p. 411-416 (2002).

[11] A. J. M. and A. Dhir, ECS transactions, 68 (1), p. 2189-2198 (2015). 
[12] F. Calise, G. Restucccia, and N. Sammes, J. Power Sources, 196 (1), p. 301-312, (2011).

[13] V. Lawlor, S. Griesser, G. Buchinger, A. G. Olabi, S. Cordiner, and D. Meissner, Journal of Fuel Cell Science and Technology, 193, p. 387-399 (2009).

[14] K. Kendall, M. Kendall, J. A. Kilner, J. Druce, and T. Ishihara, High-Temperature Solid Oxide Fuel Cells for the 21st Century, p. 85-132 (2016).

[15] A. Bertei, B. Nucci, and C. Nicolella, Chem. Eng. Sci., 101, p. 175-190 (2013).

[16] C. Jin, J. Liu, L. Li, and Y. Bai, Journal of Membrane Science, 341, p. 233-237 (2009).

[17] N. Mahato, A. Banerjee, A. Gupta, S. Omar, and K. Balani, Prog. Mater. Sci., 72, p. 141-337 (2015).

[18] K. Kendall, M. Kendall, L. Niewolak, F. Tietz, and W. J. Quadakkers, HighTemperature Solid Oxide Fuel Cells for the 21st Century, p. 195-254 (2016).

[19] K. Kendall, M. Kendall, and N. Q. Minh, High-Temperature Solid Oxide Fuel Cells for the 21st Century, p. 255-282 (2016).

[20] A. G. Sabato, G. Cempura, D. Montinaro, A. Chrysanthou, M. Salvo, E. Bernardo, M. Secco, and F. Smeacetto, J. Power Sources, 328, p. 262-270 (2016).

[21] S. A. Hajimolana, M. A. Hussain, W. M. A. W. Daud, M. Soroush, and A. Shamiri, Renew. Sustain. Energy Rev, 15( 4), p. 1893-1917 (2011).

[22] S. G. V.Lawlor, Journal of Fuel Cell Science and Technology, 10, p. 1-11 (2013).

[23] S. Hajimolana and M. Soroush, Fuel Cels, 12(5), p. $761-772$ (2012)

[24] D. Cui, L. Liu, Y. Dong, and M. Cheng, J. Power Sources, 174, p. 246-254 (2007).

[25] H. Zhu and R. J. Kee, J. Power Sources, 169, p. 315-326 (2007).

[26] COMSOL Multiphysics 5.2 Software 2016. 2016.

[27] E. N. Fuller, P. D. Schettler, and J. C. Giddings, Ind. Eng. Chem.,16(10), p. 551 (1966).

[28] K. Howe, Birmingham: University of Birmingham, 2013.

[29] D. H. Green and R.H. Perry, Perry's Chemical Engineers' Handbook. 8 ed, McGraw-Hill Professional (2007) 